\title{
Not just semantics: Strong frequency and weak cognate effects on semantic association in bilinguals
}

\author{
INÉS ANTÓN-MÉNDEZ \\ Utrecht University, Utrecht, The Netherlands \\ and University of New England, Armidale, New South Wales, Australia \\ AND \\ TAMAR H. Gollan \\ University of California, San Diego, La Jolla, California
}

\begin{abstract}
To investigate the possibility that knowledge of two languages influences the nature of semantic representations, bilinguals and monolinguals were compared in a word association task. In Experiment 1, bilinguals produced less typical responses relative to monolinguals when given cues with a very common associate (e.g., given bride, bilinguals said "dress" instead of "groom"). In Experiment 2, bilinguals produced responses as typical as those of monolinguals when given cues with high-frequency associates, but not when given cues with lowfrequency associates. Bilinguals' responses were also affected, to a certain extent, by the cognate status of the stimulus word pairs: They were more similar to monolinguals' responses when the cue and its strongest associate were both cognates (e.g., minute-second is minuto-segundo in Spanish), as opposed to both being noncognates. Experiment 3 confirmed the presence of a robust frequency effect on bilingual but not on monolingual association responses. These findings imply a lexical locus for the bilingual effect on association responses and reveal the association task to be not quite as purely semantic as was previously assumed.
\end{abstract}

Recent years have brought a flurry of articles reporting differences between bilinguals and monolinguals in a number of cognitive tasks, including bilingual advantages (tasks that bilinguals perform more quickly or efficiently than do monolinguals), bilingual disadvantages (tasks that bilinguals perform more slowly and with more errors than do monolinguals), and some simply qualitative differences (neither favorable nor unfavorable). Where population differences arise, much can be learned by attempting to identify the locus of these differences in well-articulated models of language processing, both for understanding the populations themselves and for further understanding the nature of linguistic representations.

To explain processing differences between bilinguals and monolinguals, it is thus necessary to have a detailed specification of both bilingual and monolingual languageprocessing models. Partly overlapping cognitive mechanisms have been proposed to explain bilingual advantages and disadvantages. Bilingual advantages have been assumed to implicate general mechanisms of cognitive control in bilingual language use. By virtue of having to control which language they speak, bilinguals may develop more efficient task-monitoring and task-control mechanisms (for a recent review, see Bialystok, Craik, \& Luk, 2008; Costa, Hernández, Costa, \& Sebastián-Gallés, 2009).
Bilingual disadvantages in language-processing tasks, on the other hand, could reflect the downside of this same mechanism (i.e., delays in lexical access associated with having to manage dual-language activation; for a review, see Kroll, Bobb, Misra, \& Guo, 2008), or alternatively, bilingual disadvantages could simply result from a relative frequency lag in terms of use of words in each language relative to monolinguals (for a detailed discussion, see Gollan, Montoya, Cera, \& Sandoval, 2008). By virtue of speaking each language only some of the time, bilinguals necessarily use each language less often than do monolingual users of those same languages. Indeed, the disadvantages associated with bilingualism are most apparent during the retrieval of low-frequency words (Gollan et al., 2008; Ivanova \& Costa, 2008).

Bilingual disadvantages have been found in children who named pictures with less accuracy than did monolingual children (e.g., Yan \& Nicoladis, 2009) and scored lower than did monolinguals in receptive vocabulary tests (e.g., Doyle, Champagne, \& Segalowitz, 1978; Nicoladis, 2003, 2006; Nicoladis \& Genesee, 1996; Oller, Pearson, \& Cobo-Lewis, 2007; Pearson, 1998; Pearson, Fernández, \& Oller, 1993; Rosenblum \& Pinker, 1983). Similarly, young adult bilinguals recognized written words more slowly than did monolinguals in a lexical decision task (Rans- 
dell \& Fischler, 1987), named pictures less accurately and more slowly than did monolinguals (e.g., Gollan et al., 2008; Gollan \& Silverberg, 2001; Roberts, Garcia, Desrochers, \& Hernandez, 2002), and scored lower than did matched monolinguals in standardized tests of receptive vocabulary (Bialystok et al., 2008; Portocarrero, Burright, $\&$ Donovick, 2007). In some studies, both the advantages and disadvantages of bilingualism were reported in the same participants, providing a powerful demonstration that the observed population effects are, in fact, related to knowledge of two languages, which, on one hand, improves executive control abilities, but, on the other, reduces the efficiency of lexical retrieval (e.g., Bialystok et al., 2008).

Another possibility is that some differences between bilinguals and monolinguals could arise at the level of semantic processing. Ameel, Malt, Stoms, and Van Assche (2009) asked participants to rate typicality of a number of bottle- or plate-like objects according to how well they matched different names (e.g., bottle vs. container and plate vs. bowl). Bilinguals provided ratings in both languages, and separate monolingual speakers of each of the bilinguals' two languages also provided ratings. Typicality ratings were correlated more strongly across languages in bilinguals' ratings than they were across languages in monolinguals' ratings. Further analyses suggested that bilinguals drop language-specific boundary exemplars from categories, resulting in less complex categories for bilinguals than for monolinguals, with fewer dimensions needed to differentiate between them (e.g., what makes a jar a jar instead of a bottle). The differences between bilinguals and monolinguals in the representation of category boundaries seem to suggest an effect of bilingualism at a semantic level. This conclusion raises a question as to whether some previously reported differences between bilinguals and monolinguals that were attributed to lexical processing could instead be taken as evidence of betweengroup differences in representation of meaning.

One such result is the finding that bilinguals are relatively more disadvantaged in the semantic than in the letter versions of the verbal fluency task (even when bilinguals are tested only in their more dominant language; e.g., Gollan, Montoya, \& Werner, 2002; Rosselli et al., 2000). In the semantic fluency task, speakers generate members of a meaning-based category (e.g., animals), whereas, in the letter fluency task, speakers generate members of a letter- or sound-based category (e.g., words that begin with the letter $\mathrm{S}$ ). Note that semantic fluency is generally easier than is letter fluency for monolinguals (but see Azuma et al., 1997); thus, it is not the case that bilinguals are disadvantaged only on the "more difficult" fluency task - in fact, the opposite may be said to occur. The greater effect of bilingualism on semantic than on letter fluency may reflect greater competition for selection during semantic fluency than during letter fluency (Gollan et al., 2002; Rosselli et al., 2000). Translation equivalents may be more difficult to reject in semantic fluency, because they are category exemplars; whereas, in letter-fluency translation, equivalents rarely begin with the same letter (Sandoval,
Gollan, Ferreira, \& Salmon, 2010). Alternatively, executive control advantages in bilinguals may offset bilingual disadvantages in lexical retrieval, particularly in letter fluency, which may tap executive control relatively more than semantic fluency does (Luo, Luk, \& Bialystok, 2010).

However, the greater bilingual disadvantage in semantic than in letter fluency also seems consistent with proposals that knowledge of more than one language influences the way in which semantic representations are organized. Bilinguals may be more likely to think of category exemplars that are high frequency in the nontarget language but are low frequency in the target language. Different languages and cultures activate slightly different category exemplars. For example, camel is a common animal in Israel but not in the U.S.A.; as such, an English-Hebrew bilingual may be disadvantaged relative to an English monolingual in English fluency because of increased attempts to retrieve words like camel that are relatively difficult to retrieve in English. In fact, there is evidence that, on average, bilinguals produce words of significantly lower frequency in their semantic fluency responses relative to monolinguals (Sandoval et al., 2010) — a most surprising result, given bilinguals' relative difficulty with retrieving low-frequency words (Gollan et al., 2008; Ivanova \& Costa, 2008).

Here, we further pursue the possibility of a bilingual effect on semantic processing by comparing bilinguals and monolinguals on a semantic association task. Word association responses have played "a central role in theories of language and concept processing" (De Deyne \& Storms, 2008, p. 213). If bilingualism changes the nature of semantic representations, bilinguals might be expected to produce different responses than monolinguals do in the association task. Conversely, if semantic representations are largely unaffected by the presence of different languages in a bilingual, bilinguals should perform much like monolinguals in semantic association tests, particularly when bilinguals are tested in their relatively dominant language that is richly and automatically connected with conceptual representations (Kroll \& Tokowicz, 2005). Early studies of word association responses in bilingual speakers found partial convergence of responses produced in each language (by the same person), implying that the two languages of a bilingual tap partially shared semantic representations (Kolers, 1963). More recent studies confirm this conclusion and extend it to propose that between-language overlap at the semantic level is greater for concrete words, nouns, and cognates (e.g., translation equivalents that overlap in meaning and form, such as name and the Spanish equivalent nombre; van Hell \& de Groot, 1998).

In Experiment 1, we investigated whether bilinguals and monolinguals produce different responses in the semantic association task. A finding of significant differences between groups would be consistent with the proposal that knowledge of two languages alters the nature of lexicalsemantic representations. An alternative possibility that we explore in Experiments 2 and 3 is that difficulty with lexical access may also play a role in the nature of bilingual responses in the association task. 


\section{EXPERIMENT 1}

In Experiment 1, we assessed whether bilinguals produce different associations than monolinguals in the semantic association task. In a previous study (Gollan, Salmon, \& Paxton, 2006), we suggested that more elaborate semantic processing takes place when speakers are asked to produce responses to "strong cues" that are associated with relatively few different responses, and very strongly with one response in particular. For example, given the strong cue flipper, the overwhelming majority (i.e., $80 \%$ ) of speakers say dolphin (Nelson, McEvoy, \& Schreiber, 1998). In contrast, relatively "weak cues" are weakly associated with a large number of different responses and may initiate relatively less semantic processing. For example, given the weak cue chicken, the most common associate (i.e., soup) was produced by only $9 \%$ of speakers along with 28 other weakly associated responses (fried, wings, food, leg, bird, nuggets, turkey, eggs, fat, hen, rooster, eat, feather, little, meat, sandwich, afraid, baked, barbecue, bone, breast, cutlet, dinner, dumplings, grease, neck, potpie, scared; Nelson et al., 1998). In Experiment 1 , we compared bilinguals and monolinguals in their English association responses on the association task with a manipulation of cue strength as a further index of the possible processing locus for any observed differences between groups. Cues were selected from a normative database of monolingual association responses, and participants' responses were coded for typicality using these referenced norms as a point of comparison. Because the norms were created by testing monolinguals, a semanticlocus model predicts that bilinguals' responses should resemble responses in the norms relatively less than would monolinguals' responses; in contrast, if there are no differences between bilinguals and monolinguals at the locus of semantic processing, no differences should be found in response typicality between groups.

\section{Method}

Participants. Thirty-one monolingual English speakers and 37 Spanish-English bilinguals, who were undergraduates at the University of California at San Diego, participated in Experiment 1 for course credit. Bilingual participants were early bilinguals who first learned Spanish at home and then learned English at school or preschool. The majority of Spanish-English bilinguals at UCSD report English dominance and also appear to be English dominant when tested in both languages (e.g., they name pictures more quickly in English than in Spanish [Gollan et al., 2008], and, when given the choice of using Spanish or English to name pictures, they use Spanish about $25 \%$ of the time [Gollan \& Ferreira, 2009]). A sizeable minority of bilinguals in this cohort are relatively balanced bilinguals, and only a very small minority are Spanish dominant. In particular, 9 out of the 37 bilingual participants in Experiment 1 reported being slightly more proficient in Spanish than in English (but note that some bilinguals who report slight Spanish dominance in this cohort name pictures equally quickly in English and Spanish). Approximately half of the monolinguals had some limited exposure to a second language, primarily through classroom instruction, but none reported an extended immersion experience in a language other than English. A summary of participants' characteristics can be found in Table 1.

Materials. We selected 40 cues from the Nelson et al. (1998) association normative database. (Further details about this database are available at http://cyber.acomp.usf.edu/FreeAssociation/Intro.html.) The cues varied in association strength (FSG, forward strength, or strength of association of the cue to the target) of their most common associates, which reflects the proportion of participants who produced a particular associate when given the cue word. Of the 40 cues, 20 were "strong," having one very common associate (FSG $\geq$ $0.5, M=0.71, S D=0.13$ ), and 20 were "weak," having many associates (each produced less often), according to Nelson et al.'s (1998) database (FSG $<0.1, M=0.09, S D=0.03$ ). See Appendix A for a list of the materials.

Procedure. Participants were tested individually in a quiet room. The stimulus cues were presented one by one verbally in a fixed random order by an experimenter. Participants had previously been instructed to say whatever came to mind after hearing the stimulus cue. Whenever participants did not respond to a cue, the experimenter prompted them again. Participants were encouraged to respond with one word and not to repeat answers. The experimenter wrote down each response after it was uttered. The sessions were also audiotaped for subsequent verification.

\section{Results and Discussion}

Response typicality was coded by reference to the association norms provided by Nelson et al. (1998). Responses that appeared in the norms were assigned a typicalitystrength score based on the proportion of speakers who produced that response (i.e., FSG). Responses that were not listed in the norms were excluded from analysis, but see Table 2, which shows the percentages of excluded responses in Table 2 . Note that bilinguals produced significantly more responses that were not listed in the norms than did monolinguals in the strong cue condition $[F(1,66)=$ $\left.10.64, M S_{\mathrm{e}}=0.018, p<.01, \eta_{\mathrm{p}}^{2}=.14\right]$, but there was only a trend in the direction of a bilingual-monolingual differ-

Table 1

Participant Characteristics

\begin{tabular}{|c|c|c|c|c|c|c|c|c|c|c|c|c|}
\hline \multirow[b]{3}{*}{ Characteristic } & \multicolumn{4}{|c|}{ Experiment 1} & \multicolumn{4}{|c|}{ Experiment 2} & \multicolumn{4}{|c|}{ Experiment 3} \\
\hline & \multicolumn{2}{|c|}{ Monolingual } & \multicolumn{2}{|c|}{ Bilingual } & \multicolumn{2}{|c|}{ Monolingual } & \multicolumn{2}{|c|}{ Bilingual } & \multicolumn{2}{|c|}{ Monolingual } & \multicolumn{2}{|c|}{ Bilingual } \\
\hline & $M$ & $S D$ & $M$ & $S D$ & $M$ & $S D$ & $M$ & $S D$ & $M$ & $S D$ & $M$ & $S D$ \\
\hline Age (years) & 21.2 & 4.0 & 20.2 & 1.4 & 21.0 & 3.7 & 20.6 & 4.6 & 20.4 & 1.6 & 19.7 & 1.3 \\
\hline Years of education & 14.5 & 1.6 & 14.2 & 1.3 & 14.6 & 1.5 & 14.0 & 1.6 & 14.1 & 1.0 & 13.4 & 1.0 \\
\hline Age of English exposure & \multicolumn{2}{|c|}{ N/A } & 4.8 & 2.8 & \multicolumn{2}{|c|}{ N/A } & 2.7 & 2.2 & \multicolumn{2}{|c|}{ N/A } & 4.3 & 3.5 \\
\hline Age of regular use of English & \multicolumn{2}{|c|}{ N/A } & 6.2 & 3.6 & \multicolumn{2}{|c|}{ N/A } & 4.3 & 2.0 & \multicolumn{2}{|c|}{ N/A } & 6.0 & 4.3 \\
\hline Self-rated a ability to speak English & 7.0 & 0.2 & 6.2 & 0.9 & 7.0 & 0.1 & 6.6 & 0.7 & 7.0 & 0.0 & 6.4 & 0.8 \\
\hline Self-rated ability to speak other language & 2.6 & 1.0 & 6.1 & 1.2 & 2.6 & 1.1 & 5.7 & 1.2 & 2.9 & 1.1 & 5.9 & 1.1 \\
\hline
\end{tabular}

Note-Gender (Male\%): Experiment 1 (25.8\%, monolingual; 33.3\%, bilingual), Experiment 2 (36.2\%, monolingual; 27.9\%, bilingual),

Experiment 3 (32.6\%, monolingual; $14.6 \%$, bilingual). aProficiency level based on self-ratings using a scale of $1-7$, with $1=$ little to no

knowledge and $7=$ like a native speaker. 
Table 2

Mean Response Typicality (Association Strength)

of Responses Given by Bilinguals and Monolinguals to Strong

and Weak Cues in Experiment 1, and Rate of Production of Responses Not Found in the Norms

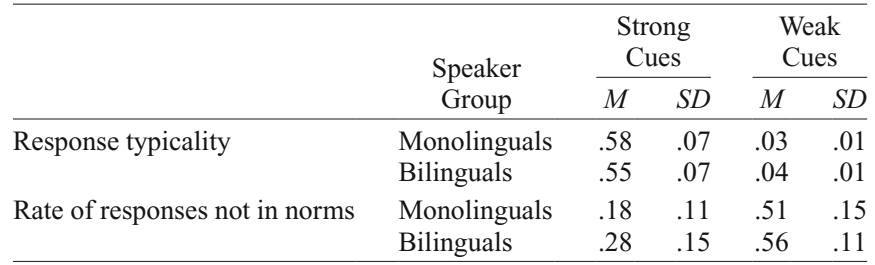

ence in the weak cue condition $\left[F(1,66)=2.89, M S_{\mathrm{e}}=\right.$ $\left.0.016, p=.09, \eta_{\mathrm{p}}^{2}=.04\right]$, in which over $50 \%$ of the responses produced by both participant groups were not listed in the norms. The reason to exclude these responses was to avoid making assumptions as to what typicality values to assign to them. Furthermore, excluding them was the most conservative option, given the pattern of excluded responses found in the different conditions.

Response association strengths were submitted to a $2 \times 2$ ANOVA with speaker group (bilingual and monolingual) and cue type (strong and weak) as nonrepeated and repeated factors, respectively. (Item trends can be found in Appendix A, which lists differences between speaker groups for each individual item.)

The results of this series of tests showed that bilinguals' overall response typicality did not differ significantly from that of monolinguals $\left[F(1,66)=2.36, M S_{\mathrm{e}}=0.003\right.$, $\left.p=.13, \eta_{\mathrm{p}}^{2}=.04\right]$, and that all speakers produced more common associates when given strong cues than when given weak cues [see Table $2 ; F(1,66)=3,435.55, M S_{\mathrm{e}}=$ $\left.0.003, p<.01, \eta_{\mathrm{p}}^{2}=.98\right]$. However, strong cues produced a larger difference between bilinguals and monolinguals; the interaction between participant type and cue type was just significant $\left[F(1,66)=3.86, M S_{\mathrm{e}}=0.003, p=.05\right.$, $\left.\eta_{\mathrm{p}}^{2}=.06\right]$. Planned contrasts revealed a marginally significant difference between bilinguals and monolinguals both for weak cues $\left[F(1,66)=2.97, M S_{\mathrm{e}}=0.000, p=\right.$ $\left..08, \eta_{\mathrm{p}}^{2}=.04\right]$ and for strong cues $\left[F(1,66)=3.12, M S_{\mathrm{e}}=\right.$ $\left.0.005, p=.08, \eta_{\mathrm{p}}^{2}=.05\right]$. However, whereas strong cues produced an effect in the predicted direction (with bilinguals producing less typical responses than monolinguals), weak cues tended in the opposite direction.

The results of Experiment 1 suggest that bilingualism leads speakers to produce significantly different association responses from monolinguals. In particular, when given strong cues, bilinguals were significantly more likely to produce responses that were not listed in the norms. Even when considering only responses speakers produced that were listed in the norms, bilinguals exhibited a trend toward producing less typical responses on average than did monolinguals for strong cues, but not when they were given weak cues. Importantly, the measure of response typicality that we used (association strength or FSG from the Nelson et al., 1998, norms) is based on monolinguals' preferences. As such, the classification of bilinguals' responses as being "atypical" cannot be taken literally, and the label "different" is more appropriate. All that this difference on its own tells us is that bilinguals' semantic network may be different from that of monolinguals - a claim that potentially has important implications for understanding the nature of semantic representations. The interesting question is how and why the difference between groups arises. Monolinguals differ from bilinguals, not just in the number of languages they speak, but also in other dimensions that may affect the sort of semantic representations formed and the associations established between them. What is more, bilinguals differ from monolinguals in several linguistic measures that could influence their performance in the association task, even if the task itself can be considered highly semantic in nature (de Groot, 1989). In this sense, lower association strength in bilinguals' responses does not imply that bilinguals' semantic representations are "deviant" with respect to monolinguals, or even that semantic associations are weaker for bilinguals.

Our finding that the bilingual effect was stronger for cues with strong associates than for cues with weak associates provides some clues about the locus of the difference between speaker groups. If association to strong cues is a more sensitive measure of the nature of semantic processing (Gollan et al., 2006), this result could be taken to suggest that bilinguals and monolinguals largely establish a similar semantic network and that only elaborate semantic processing reveals what amounts to very small differences between groups. This interpretation would, in any event, offer some support for the proposal that bilingualism influences the nature of lexical-semantic representations. Because bilinguals completed the association task exclusively in English, this analysis would further imply an influence of their knowledge of Spanish on association responses in English.

However, weak associates may simply be less sensitive to between-group differences because of floor effects. Without a manipulation of nonsemantic factors, there is little possibility of identifying the locus of the bilingual effect on association responses. What is needed is to ask whether nonsemantic variables influence bilinguals' responses in the association task. It has been suggested that the association task primarily reflects semantic processing and is not influenced by lexical accessibility. Supporting this claim, imageability, but not word frequency, was a powerful predictor of association responses (de Groot, 1989; see also Nelson, Dyrdal, \& Goodmon, 2005); speakers were faster to produce associations to highly image- 
able cues than to low-imageability cues, but differences in cue frequency had negligible effects (if anything, speakers produced associations to high-frequency cues more slowly than they did to low-frequency cue words).

Because word frequency is known to affect lexical retrieval (for a recent review, see Kittredge, Dell, Verkuilen, \& Schwartz, 2008), the absence of a frequency effect on association responses implies that the association task primarily reflects semantic processing, and remains relatively unaffected by lexical accessibility. However, null effects are always difficult to interpret. It is possible that the association task is affected by lexical accessibility of the strongest associate, but that this could not be detected in previous studies that focused only on cue frequency (de Groot, 1989). On this view, bilinguals' responses in semantic association should differ from those of monolinguals only when bilinguals have difficulty retrieving the lexical labels of the associates that come to mind. In Experiment 2, we tested whether factors that facilitate retrieval for bilinguals attenuate (or even eliminate) the bilingual effect on association responses.

\section{EXPERIMENT 2}

Although knowledge of two languages makes lexical access more difficult in some language tasks, it is possible to reduce or eliminate these bilingual disadvantages by manipulating the nature of the materials. For example, bilinguals access translation equivalents that are formally similar in their two languages, or cognates (e.g., artery is arteria in Spanish), more easily than they do words that have dissimilar translation equivalents, or noncognates (e.g., dustpan is recogedor in Spanish). In some cases, manipulation of cognate status eliminates the bilingual disadvantage in lexical access (Gollan \& Acenas, 2004). Numerous studies document these "cognate facilitation effects," even when bilinguals are tested exclusively in their relatively more dominant language.

The observation of cognate effects in the dominant language is important in the present context, because it indicates that the less dominant language can influence the dominant language, and - for the majority of bilinguals in Experiment 1-it was the dominant language that revealed a bilingual effect. Cognate effects in the dominant language have been reported in both recognition (e.g., van Hell \& Dijkstra, 2002) and production in both young (Costa, Caramazza, \& Sebastián-Gallés, 2000) and aging bilinguals (Gollan, Fennema-Notestine, Montoya, \& Jernigan, 2007). In the present context, if cognates reduce the difference between bilinguals' and monolinguals' association responses, this would increase confidence that knowledge of two languages influences the nature of association responses and would help identify the locus of the differences between groups.

Another variable that increases lexical accessibility is word frequency, and there is evidence that frequency especially affects lexical accessibility in bilingual language production. Two recent studies (Gollan et al., 2008; Ivanova \& Costa, 2008) demonstrated that slowing related to bilingualism in the picture-naming task was greater for naming pictures with low-frequency names (e.g., frog) than for naming pictures with high-frequency names (e.g., dog). Stated differently, when bilinguals named pictures (in their dominant language) they demonstrated a larger frequency effect than did monolinguals. Although there is some debate about the locus of word frequency effects in language production (e.g., Alario, Costa, \& Caramazza, 2002; Dell, 1990; Griffin \& Bock, 1998; Jescheniak \& Levelt, 1994; Kittredge et al., 2008; Santesteban, Costa, Pontin, \& Navarrete, 2006), there is a consensus that frequency effects arise during lexical selection, and specifically not during prelexical semantic processing (for a recent review, see Almeida, Knobel, Finkbeiner, \& Caramazza, 2007). As such, the modulation of the bilingual disadvantage in picture naming by frequency implies an influence of bilingualism on lexical accessibility. In a similar vein, if the bilingual effect on semantic association is modulated by associate frequency, it would localize the effect at a nonsemantic lexical-retrieval locus, and, more broadly, it would imply that the association task does not reflect semantic processing exclusively.

In Experiment 2, we again compared bilinguals and monolinguals, exclusively examining cues with strong associates with four types of cue-associate pairings. At the two extremes, we had (1) cognate-cognate pairs (in which both the cue and its most common associate are SpanishEnglish cognates) and (2) noncognate-noncognate pairs (in which both the cue and its most common associate are noncognates); we also included (3) cognate-noncognate and (4) noncognate-cognate pairs. Assuming that cognate status could facilitate cue and associate retrieval, bilinguals' responses would be predicted to most resemble those of monolinguals for pairs in which both cue and most-common associate are cognates (cognate-cognate cue-target pairs). Conversely, bilinguals' responses should differ most from those of monolinguals for noncognate cues with a most-common associate that is also a noncognate (i.e., noncognate-noncognate cue-target pairs).

Within each condition, we also included a range of word frequency of the most common associate (while controlling frequency between conditions). Although prior work has identified the association task to be relatively insensitive to word frequency effects (both in frequency of the cue [de Groot, 1989] and in frequency of the associated words [Nelson et al., 2005]), we hypothesized that bilinguals' performance in the association task may nevertheless reveal a role for frequency of the associate because of bilinguals' greater sensitivity to frequency in production tasks (Gollan et al., 2008; Ivanova \& Costa, 2008).

If the differences we observed between monolinguals and bilinguals in the semantic association task in Experiment 1 were caused by bilinguals' difficulty in accessing the names of common associates, we should find a smaller effect of bilingualism on the association task when the most common associate is a high-frequency word and a larger difference between bilinguals and monolinguals when the most common associate is a low-frequency word. Conversely, if the bilingual effect on the semantic association task arises exclusively at the level of semantic processing, there should be no modulation of the bilin- 
gual effect by frequency (i.e., bilinguals should produce less typical associates from monolinguals, even when cues have common associates that are high-frequency words, and to an equal extent for cues with high- vs. lowfrequency associates).

\section{Method}

Participants. We selected 71 monolingual English speakers and 68 Spanish-English bilinguals from the same population from which participants were drawn in Experiment 1. Three speakers had to be excluded from the analyses: 2 monolinguals, because of technical problems during the testing, and 1 bilingual, because he was trilingual (also spoke Chinese from an early age). As reported above, most bilinguals in the cohort from which our participants came are relatively balanced or English-dominant bilinguals. In particular, in Experiment 2, only 3 participants reported being dominant in Spanish. A summary of the participants' characteristics can be found in Table 1.

Materials. A list of 72 cues was selected based on the normative database published by Nelson et al. (1998). Of these, 36 were cognates and 36 were noncognates. Each of these types was further divided in two, with half of the cues being strongly associated to a cognate and half being strongly associated to a noncognate, resulting in four conditions (cognate-cognate, cognate-noncognate, noncognate-cognate, and noncognate-noncognate). The four conditions were matched for association strength according to Nelson et al.'s (1998) norms, as well as mean frequency of cue and target (all $p \mathrm{~s}>.17$ ).

It was not possible to find enough materials to create a full factorial manipulation of cognate status and word frequency count of most-common associate (high, low). However, to enable us to consider the possible effects of associate frequency on the bilingual effect on semantic association, within each of the four conditions, we attempted to include associates with a range of frequencies such that approximately half (as close as possible given the other restrictions) of the most common associates were high frequency and half were low frequency, with a cutoff of 70 counts per million (CELEX; Baayen, Piepenbrock, \& Gulikers, 1995). Appendix B contains the list of cues, their most common semantic associates, their Spanish translations, the frequency count of each associate, and the frequency level for purposes of analysis.

All cues were presented to each participant in one of four randomized orders, with roughly equal numbers of participants tested in each list.

Procedure. The procedure was the same as in Experiment 1, except that speakers were allowed to repeat words, because a few of the most common associates were the same for different target cues (see Appendix B).

\section{Results and Discussion}

In all four conditions, bilinguals produced significantly more responses that were not in the norms than did mono- linguals (all $p \mathrm{~s} \leq .04)$. The rate of these responses is listed in Table 3, and, as was the case in Experiment 1, we excluded these responses from further analyses.

Cognate effects. Response typicality was coded by reference to the association norms provided by Nelson et al. (1998), as was the case in Experiment 1. In Experiment 2 , responses were also coded with respect to whether they were the most common associate listed in the Nelson et al. (1998) norms. Table 3 shows the mean association strength (from the Nelson et al. [1998] norms) of the responses produced in each condition for the two speaker groups. Supporting the predictions outlined above, the greatest difference between bilinguals and monolinguals in mean association strength (i.e., mean response typicality) was obtained in the noncognate-noncognate condition, and the difference was comparatively much smaller (and no longer significant; see below) in the cognatecognate condition.

Response association strengths were submitted to a $2 \times 4$ ANOVA, with participant type (monolingual and bilingual) as a between-subjects factor and condition as a repeated measures factor. (Item trends can be found in Appendix $B$, which lists differences between speaker groups for each individual item.) Results showed that bilinguals produced less typical associates overall compared with monolinguals $\left[F(1,135)=10.80, M S_{\mathrm{e}}=0.004, p<.01\right.$, $\left.\eta_{\mathrm{p}}^{2}=.07\right]$. There were significant differences between conditions $\left[F(3,405)=11.99, M S_{\mathrm{e}}=0.003, p<.01, \eta_{\mathrm{p}}^{2}=\right.$ .08], but this difference did not seem to be modulated by bilingual status [the expected interaction between cognateness and speaker group was not significant; $F(3,405)=$ $\left.1.73, M S_{\mathrm{e}}=0.003, p=.16, \eta_{\mathrm{p}}^{2}=.01\right]$.

Given the lack of significant interaction when the four conditions were considered, we decided to focus our analyses on the two extreme conditions - cue-associate pairs that were both cognates (cognate-cognate) and those that were both noncognates (noncognate-noncognate). Planned comparisons revealed no significant difference between bilinguals and monolinguals for cognate-cognate items $\left[F(1,135)=1.07, M S_{\mathrm{e}}=0.01, p=.30, \eta_{\mathrm{p}}^{2}=.01\right]$, a significant difference between bilinguals and monolinguals for noncognate-noncognate items $[F(1,135)=13.99$, $\left.M S_{\mathrm{e}}=0.01, p<.01, \eta_{\mathrm{p}}^{2}=.09\right]$, and a significant interaction between condition and speaker group $[F(1,135)=$ $\left.4.13, M S_{\mathrm{e}}=0.01, p=.04, \eta_{\mathrm{p}}^{2}=.03\right]$. This analysis con-

Table 3

Mean Response Typicality (Association Strength), Rate of Production of Responses Not Found in the Norms, and Probability of Producing the Most Common Associate With Respect to Cognate Status in Experiment 2

\begin{tabular}{|c|c|c|c|c|c|c|c|c|c|}
\hline \multirow[b]{2}{*}{ Condition } & \multirow{2}{*}{$\begin{array}{l}\text { Speaker } \\
\text { Group }\end{array}$} & \multicolumn{2}{|c|}{$\begin{array}{c}\text { Cognate- } \\
\text { Cognate }\end{array}$} & \multicolumn{2}{|c|}{$\begin{array}{l}\text { Cognate- } \\
\text { Noncognate }\end{array}$} & \multicolumn{2}{|c|}{$\begin{array}{c}\text { Noncognate- } \\
\text { Cognate }\end{array}$} & \multicolumn{2}{|c|}{$\begin{array}{l}\text { Noncognate- } \\
\text { Noncognate }\end{array}$} \\
\hline & & $M$ & $S D$ & $M$ & $S D$ & $M$ & $S D$ & $M$ & $S D$ \\
\hline \multirow[t]{2}{*}{ Response typicality } & Monolinguals & .38 & .07 & .36 & .05 & .39 & .06 & .37 & .05 \\
\hline & Bilinguals & .37 & .06 & .34 & .06 & .38 & .06 & .34 & .06 \\
\hline \multirow[t]{2}{*}{ Rate of responses not in norms } & Monolinguals & .19 & .10 & .17 & .11 & .21 & .14 & .17 & .11 \\
\hline & Bilinguals & .23 & .12 & .23 & .13 & .29 & .13 & .22 & .12 \\
\hline \multirow[t]{2}{*}{ Probablity strongest associate ${ }^{a}$} & Monolinguals & .49 & .12 & .43 & .12 & .45 & .13 & .44 & .12 \\
\hline & Bilinguals & .44 & .13 & .38 & .13 & .39 & .12 & .36 & .14 \\
\hline
\end{tabular}

aProbability strongest associate $=$ probability of producing the strongest or most common associate. 
firmed that the bilingual effect on semantic association is largest when bilinguals were asked to respond to noncognate cues whose most common associate is also a noncognate and is smallest (and not significantly different) when bilinguals responded to cognate cues whose most common associate is also a cognate.

Additionally, we considered the possibility that the cognate effect may depend on whether it is the cue or the associate that is a cognate. That is, there may be differences in the effect of cognateness during comprehension (cue cognateness) and production (associate cognateness). Although an effect of the cognate status of the cue would be more likely to reflect underlying differences in the semantic networks of bilinguals with respect to those of monolinguals, an effect of the cognate status of the associate would be more likely to be due to the relative ease of production of cognates versus noncognates for bilinguals. A $2 \times 2 \times 2$ ANOVA with cue and associate cognateness as within-subjects variables and speaker group as a betweensubjects variable showed that the cognate status of cue was not significant $(p=.31)$, but showed a significant effect of cognate status of the associate $(p<.01)$. However, the interactions between cue or associate cognate status and speaker group failed to reach significance ( $p \mathrm{~s}=.17$ and .15 , respectively). Thus, these results confirm our conclusion that the cognate effect is not due to cognateness playing a role, either primarily during comprehension or during production, but rather to a combination of the cognateness of the two words in the association pair facilitating responses for bilinguals.

Having found no difference in response typicality between speaker groups for cognate-cognate pairs, we conducted a secondary analysis to consider more precisely how cognate status influenced bilinguals' association responses. Specifically, we asked whether the cognate effects we observed were caused by an increased likelihood that bilinguals would produce the most common associate for cognate-cognate than for noncognate-noncognate pairs. For these analyses, we divided participants' responses into two categories - those in which the most common associate had been produced and those in which an alternative associate had been produced (according to the Nelson et al., 1998, norms). The means are shown in Table 3. As expected, bilinguals were more likely to produce the strongest associate in the cognate-cognate than in the noncognate-noncognate condition $[F(1,67)=$ $\left.20.86, M S_{\mathrm{e}}=0.01, p<.01, \eta_{\mathrm{p}}^{2}=.24\right]$. However, although we matched materials across conditions for forward association strength, this was also true for monolinguals $\left[F(1,68)=6.75, M S_{\mathrm{e}}=0.01, p<.05, \eta_{\mathrm{p}}^{2}=.09\right]$, implying that something other than cognate status differs between conditions. More importantly, the interaction indicating that bilinguals may have benefitted more from cognate status than did monolinguals trended in the right direction, but was not significant $\left[F(1,135)=2.26, M S_{\mathrm{e}}=0.01\right.$, $\left.p=.14, \eta_{\mathrm{p}}^{2}=.02\right]$. In addition, bilinguals were still significantly less likely than were monolinguals to produce the most common associate in the cognate-cognate condition (and more generally, in all four conditions, all $p \mathrm{~s}<$ $.03)$. These analyses imply that more than one factor led bilinguals to produce similarly typical responses overall relative to monolinguals on the cognate-cognate pairs. ${ }^{1}$

Because bilinguals sometimes perform more similarly in their two languages if the targets are concrete, there was some concern that concreteness might be driving these effects. We found a significant difference between conditions with respect to cue concreteness and associate concreteness (both $p \mathrm{~s}<.05$ ). However, in both cases, cognate cues were more abstract than were noncognate cues, resulting in bilinguals behaving more like monolinguals when both cue and target were more abstract. Since the differences between conditions for the two speaker groups would run counter to expectations if the relevant factor was concreteness, it is more likely that the effect is instead due to the cognateness manipulation.

Frequency effects. Turning to the possible role of associate frequency on bilinguals' responses, we first considered whether the frequency of the most common associate affected response typicality. Table 4 shows response typicality for the two speaker groups by frequency level. A $2 \times 2$ ANOVA comparing frequency level (high- vs. low-frequency associate) as a repeated measures factor and speaker group (bilinguals vs. monolinguals) as a betweensubjects factor with response FSGs as the dependent variable again revealed that bilinguals produced significantly different responses than did monolinguals $[F(1,135)=$ $\left.11.95, M S_{\mathrm{e}}=0.002, p<.01, \eta_{\mathrm{p}}^{2}=.08\right]$. There was no overall effect of associate frequency $\left[F(1,135)=1.93, M S_{\mathrm{e}}=\right.$ $\left.0.002, p=.17, \eta_{\mathrm{p}}^{2}=.01\right]$, but this finding was qualified by a significant interaction between associate frequency and speaker group $\left[F(1,135)=4.90, M S_{\mathrm{e}}=0.002, p<.05\right.$, $\left.\eta_{\mathrm{p}}^{2}=.04\right]$, which revealed that the bilingual effect on association responses was more pronounced for cues with lowfrequency associates. Planned comparisons showed that bi-

Table 4

Mean Response Typicality (Association Strength) and Probability of Producing the Most Common Associate With Respect to Frequency Level in Experiment 2

\begin{tabular}{|c|c|c|c|c|c|}
\hline \multirow[b]{2}{*}{ Condition } & \multirow{2}{*}{$\begin{array}{l}\text { Speaker } \\
\text { Group }\end{array}$} & \multicolumn{2}{|c|}{$\begin{array}{c}\text { High-Frequency } \\
\text { (>70 Counts/ } \\
\text { Million) } \\
\text { Associate }\end{array}$} & \multicolumn{2}{|c|}{$\begin{array}{c}\text { Low-Frequency } \\
\text { (<70 Counts/ } \\
\text { Million) } \\
\text { Associate }\end{array}$} \\
\hline & & $M$ & $S D$ & $M$ & $S D$ \\
\hline Response typicality & $\begin{array}{l}\text { Monolinguals } \\
\text { Bilinguals }\end{array}$ & $\begin{array}{l}.37 \\
.37\end{array}$ & $\begin{array}{l}.04 \\
.04\end{array}$ & $\begin{array}{l}.38 \\
.35\end{array}$ & $\begin{array}{l}.05 \\
.06\end{array}$ \\
\hline Probability of producing strongest associate & $\begin{array}{l}\text { Monolinguals } \\
\text { Bilinguals }\end{array}$ & $\begin{array}{l}.45 \\
.43\end{array}$ & $\begin{array}{l}.12 \\
.11\end{array}$ & $\begin{array}{l}.45 \\
.35\end{array}$ & $\begin{array}{l}.10 \\
.12\end{array}$ \\
\hline
\end{tabular}


linguals differed from monolinguals when the associate had a low-frequency count $\left[F(1,135)=13.27, M S_{\mathrm{e}}=0.003\right.$, $p<.01, \eta_{\mathrm{p}}^{2}=.09$ ], but not when the associate was a highfrequency word $\left[F(1,135)=1.65, M S_{\mathrm{e}}=0.002, p=.20\right.$, $\left.\eta_{\mathrm{p}}^{2}=.01\right]$. In addition, as reported by Nelson et al. (2005), monolinguals did not seem to show any effect of associate frequency at all $(F<1)$. However, bilinguals exhibited a robust frequency effect on response typicality $[F(1,67)=$ $\left.6.02, M S_{\mathrm{e}}=0.002, p<.05, \eta_{\mathrm{p}}^{2}=.08\right]$.

As above, we also considered how associate frequency influenced bilinguals' responses by asking whether high associate frequency increased the chance that bilinguals would produce the most common associate. Table 4 shows the probability of responding with the most common associate for the two speaker groups according to frequency level. A $2 \times 2$ ANOVA contrasting frequency level (highvs. low-frequency associate) as a repeated measures factor and speaker group (bilinguals vs. monolinguals) as a between-subjects factor showed that overall speakers were more likely to produce the most common associate for cues that had a high-frequency associate than for cues that had a low-frequency associate $\left[F(1,135)=10.85, M S_{\mathrm{e}}=\right.$ $\left.0.01, p<.01, \eta_{\mathrm{p}}^{2}=.07\right]$. In addition, bilinguals were less likely to produce the most common associate than were monolinguals $\left[F(1,135)=18.86, M S_{\mathrm{e}}=0.01, p<.01\right.$, $\left.\eta_{\mathrm{p}}^{2}=.12\right]$. However, both main effects were qualified by a significant interaction between associate frequency and speaker group $\left[F(1,135)=10.91, M S_{\mathrm{e}}=0.01, p<.01\right.$, $\left.\eta_{\mathrm{p}}^{2}=.08\right]$. Planned comparisons revealed that bilinguals were less likely than were monolinguals to produce the most common associate only when the associate had a low-frequency count $\left[F(1,135)=30.01, M S_{\mathrm{e}}=0.01, p<\right.$ $\left..01, \eta_{\mathrm{p}}^{2}=.18\right]$, but this effect of speaker group was no longer significant for cues when the associate was a highfrequency word $\left[F(1,135)=1.44, M S_{\mathrm{e}}=0.01, p=.23\right.$, $\left.\eta_{\mathrm{p}}^{2}=.01\right]$. In addition, monolinguals did not show any effect of frequency $(F<1)$, whereas bilinguals exhibited a robust frequency effect on the probability of producing the most common associate $\left[F(1,67)=23.88, M S_{\mathrm{e}}=\right.$ $\left.0.01, p<.01, \eta_{\mathrm{p}}^{2}=.26\right]$. These analyses imply that the difference in performance between monolinguals and bilinguals with respect to response typicality is due to a frequency effect, to which only bilinguals are susceptible, on the probability of producing the most common associate.

Independence of cognate and frequency effects. Having observed robust frequency effects and some evidence of cognate effects on association responses in bilinguals, a remaining question concerned the extent to which these effects are independent of each other. Importantly, we controlled for frequency across condition; therefore, the cognate effects we obtained could not be attributed exclusively to associate frequency, and vice versa. However, given that we were not able to find sufficient materials for a full-factorial manipulation of cognateness and frequency, it remained possible that part of the frequency effect we observed was due to cognate status. To check whether this might be the case, we reclassified conditions according to whether the associate was a cognate and ran a $2 \times 2 \times 2$ ANOVA on probability of producing the most common associate with speaker group as a nonrepeated factor and cognate status of the associate and frequency as repeated factors. The interaction between cognateness and frequency reflecting a higher probability of producing the most common associate when this associate was both a high-frequency word and a cognate was marginally significant $(p=.06)$, whereas the three-way interaction between speaker group, cognateness, and frequency was significant at the 0.03 level. The interaction between associate cognateness and frequency, furthermore, proved to be significant only for bilinguals $(p<.01)$, but not for monolinguals $(p=.85)$. It seems, therefore, that word frequency of the most common associate and cognate status play independent roles in modulating the bilingual effect on semantic association responses.

Although the finding of a cognate effect on association responses is likely to reflect the relatively greater lexical accessibility of cognates for bilinguals, it has also been argued (e.g., van Hell \& de Groot, 1998) that cognate effects could arise at a semantic processing level. On this view, translation equivalents overlap to a greater extent at a semantic level when they are formally similar between languages. In contrast, as reviewed above, there is general agreement that frequency effects arise at a postsemantic locus. Thus, to increase our confidence in the conclusion that bilinguals produce different associations, at least in part because of difficulty with retrieving certain associates, we conducted another experiment focusing exclusively on frequency of the associate.

\section{EXPERIMENT 3}

As an additional test of our hypothesis that bilinguals' difficulty with lexical access during language production influences the nature of their responses in the word association task, we conducted a third experiment with a more powerful word frequency manipulation and also controlled for number of translations and concreteness (Tokowicz \& Kroll, 2007) and other variables that could influence the nature of bilinguals' responses.

\section{Method}

Participants. We selected 46 monolingual English speakers and 48 Spanish-English bilinguals from the same population from which the participants in Experiments 1 and 2 were drawn. Most bilingual participants reported similar proficiency in Spanish and English. Of the 48,10 reported being slightly more proficient in Spanish. Table 1 summarizes participant characteristics.

Materials. Stimuli consisted of 31 cues for which the strongest associate was a low-frequency item ( $<70$ counts per million; CELEX; Baayen et al., 1995) and 31 cues for which the strongest associate was a high-frequency lexical item ( $>70$ counts per million). Table 5 shows the materials characteristics. Across the manipulation of associate frequency, the materials were matched for associate typicality (FSG), associate number of translations into Spanish, associate concreteness, associate length in syllables, cue frequency, cue number of translations into Spanish, cue concreteness, and cue length in syllables. Number of translations was determined by asking 5 native Spanish-English bilinguals (who did not participate in the present experiments) to translate the cues and their associates from English to Spanish. Morphological variants were not counted as separate translations (e.g., banquero/banquera). In addition, we matched the cue-associate pairs in the high- and low-frequency conditions for the extent to which the relationship between them is strictly associative versus more purely semantic. Associative versus semantic relation- 
Table 5

Characteristics of Cue-Associate Pairs in Experiment 3

\begin{tabular}{|c|c|c|c|c|c|c|}
\hline & \multicolumn{2}{|c|}{$\begin{array}{c}\text { High-Frequency } \\
\text { (>70 Counts/Million) } \\
\text { Associate Condition } \\
\end{array}$} & \multicolumn{2}{|c|}{$\begin{array}{c}\text { Low-Frequency } \\
\text { (<70 Counts/Million) } \\
\text { Associate Condition }\end{array}$} & \multirow[b]{2}{*}{$t$} & \multirow[b]{2}{*}{$p$} \\
\hline & $M$ & $S D$ & $M$ & $S D$ & & \\
\hline Forward association strength ${ }^{\mathrm{a}}$ & .58 & .12 & .59 & .12 & $<1$ & .84 \\
\hline Associate frequency & 227.55 & 258.00 & 21.55 & 19.03 & 11.55 & $<.01$ \\
\hline Associate number of translations & 1.68 & 0.70 & 1.71 & 0.97 & $<1$ & .88 \\
\hline Associate concreteness ${ }^{\mathrm{a}, \mathrm{b}}$ & 5.50 & 0.90 & 5.52 & 0.89 & $<1$ & .93 \\
\hline Associate length in syllables & 1.35 & 0.55 & 1.35 & 0.55 & $<1$ & 1.00 \\
\hline Cue frequency & 27.49 & 43.05 & 27.10 & 42.99 & $<1$ & .97 \\
\hline Cue number of translations & 1.58 & 0.76 & 1.45 & 0.81 & $<1$ & .52 \\
\hline Cue concreteness ${ }^{\mathrm{a}, \mathrm{c}}$ & 5.43 & 1.04 & 5.31 & 1.03 & $<1$ & .69 \\
\hline Cue length in syllables & 1.45 & 0.51 & 1.42 & 0.50 & $<1$ & .80 \\
\hline Associative versus semantic & -0.25 & 3.70 & -0.29 & 4.03 & $<1$ & .97 \\
\hline
\end{tabular}

aResponse typicality of strongest associate taken from the Nelson, McEvoy, and Schreiber (1998) norms. bValues available in Nelson et al. (1998) norms for 30/31 associates in both high- and low-frequency conditions. cValues available in Nelson et al. (1998) norms for 27/31 cues in high- and 25/31 cues in low-frequency condition. ${ }^{\mathrm{d} B a s e d}$ on ratings with a scale in which $-7=$ occur together but do not overlap in meaning, $0=$ occur together and overlap in meaning, 7 = overlap in meaning but do not occur together.

ship was assessed with subjective ratings from 5 people with knowledge of psycholinguistics (either a $\mathrm{PhD}$ or graduate-level work) of the extent to which pairs were related associatively, semantically, or both. On average, the pairs tended to be both lexically and semantically associated, but there was a fair amount of variability in these ratings in both frequency groups (see Table 5; but note that recent conceptualizations of meaning representation frame the distinction between associative and semantic relationships as arbitrary; Hare, Jones, Thomson, Kelly, \& McRae, 2009).

Appendix C contains the list of cues, their most common semantic associates, their Spanish translations, and the frequency count of cue and associate. All cues were presented to each participant in one of four randomized orders, with roughly equal numbers of participants tested in each list.

Procedure. The procedure was the same as that followed in Experiment 2.

\section{Results and Discussion}

As in Experiment 2, bilinguals were significantly more likely than were monolinguals to produce responses not listed in the Nelson et al. (1998) norms in both high- and low-frequency associate conditions (both $p$ s $<.01$ ). The rates of these responses by speaker group and conditions are shown in Table 6, and, as in Experiments 1 and 2, we excluded these responses from further analysis.
A $2 \times 2$ ANOVA contrasting frequency level (highvs. low-frequency associate) as a repeated measures factor and speaker group (bilinguals vs. monolinguals) as a between-subjects factor with typicality (or association strength) of responses as the dependent variable revealed that bilinguals produced less typical responses overall in comparison with monolinguals (see Table 6); this main effect of speaker group was highly robust $[F(1,94)=12.95$, $\left.M S_{\mathrm{e}}=0.005, p<.01, \eta_{\mathrm{p}}^{2}=.12\right]$. In addition, cues with high-frequency associates elicited more typical responses than did cues with low-frequency associates $[F(1,94)=$ $\left.17.98, M S_{\mathrm{e}}=0.002, p<.01, \eta_{\mathrm{p}}^{2}=.16\right]$. However, both main effects were qualified by a significant interaction between participant type and associate frequency $[F(1,94)=$ $\left.8.13, M S_{\mathrm{e}}=0.002, p<.01, \eta_{\mathrm{p}}^{2}=.08\right]$, reflecting the fact that bilinguals were more sensitive than were monolinguals to the frequency manipulation. Planned comparisons showed a frequency effect on bilinguals' response typicality $\left[F(1,47)=18.45, M S_{\mathrm{e}}=0.003, p<.01, \eta_{\mathrm{p}}^{2}=.28\right]$ but not in monolinguals' response typicality $[F(1,47)=1.52$, $\left.M S_{\mathrm{e}}=0.001, p=.23, \eta_{\mathrm{p}}^{2}=.03\right]$. Furthermore, the difference between monolinguals and bilinguals was significant for cues with low-frequency associates $[F(1,94)=16.60$,

Table 6

Mean Response Typicality (Association Strength), Rate of Production of Responses Not Found in the Norms, and Probability of Producing the Most Common Associate With Respect to Frequency Level in Experiment 3

\begin{tabular}{|c|c|c|c|c|c|}
\hline \multirow[b]{2}{*}{ Condition } & \multirow{2}{*}{$\begin{array}{l}\text { Speaker } \\
\text { Group }\end{array}$} & \multicolumn{2}{|c|}{$\begin{array}{c}\text { High-Frequency } \\
\text { (>70 Counts/Million) } \\
\text { Associate }\end{array}$} & \multicolumn{2}{|c|}{$\begin{array}{c}\text { Low-Frequency } \\
(<70 \text { Counts/Million }) \\
\text { Associate }\end{array}$} \\
\hline & & $M$ & $S D$ & $M$ & $S D$ \\
\hline Response typicality & $\begin{array}{l}\text { Monolinguals } \\
\text { Bilinguals }\end{array}$ & $\begin{array}{l}.45 \\
.43\end{array}$ & $\begin{array}{l}.05 \\
.05\end{array}$ & $\begin{array}{l}.44 \\
.38\end{array}$ & $\begin{array}{l}.04 \\
.08\end{array}$ \\
\hline Rate of responses not in norms & $\begin{array}{l}\text { Monolinguals } \\
\text { Bilinguals }\end{array}$ & $\begin{array}{l}.18 \\
.27\end{array}$ & $\begin{array}{l}.09 \\
.13\end{array}$ & $\begin{array}{l}.20 \\
.31\end{array}$ & $\begin{array}{l}.09 \\
.14\end{array}$ \\
\hline Probability of producing strongest associate & $\begin{array}{l}\text { Monolinguals } \\
\text { Bilinguals }\end{array}$ & $\begin{array}{l}.57 \\
.50\end{array}$ & $\begin{array}{l}.11 \\
.12\end{array}$ & $\begin{array}{l}.55 \\
.42\end{array}$ & $\begin{array}{l}.10 \\
.15\end{array}$ \\
\hline
\end{tabular}


$\left.M S_{\mathrm{e}}=0.004, p<.01, \eta_{\mathrm{p}}^{2}=.15\right]$ but was no longer significant for cues with high-frequency associates $[F(1,94)=$ $\left.2.55, M S_{\mathrm{e}}=0.002, p=.11, \eta_{\mathrm{p}}^{2}=.03\right]$.

As in Experiment 2, we also considered whether the frequency of the most typical associate affected the probability that bilinguals would, in fact, produce that associate in a $2 \times 2$ ANOVA with frequency level (high- vs. low-frequency associate) as a repeated measures factor, with speaker group (bilinguals vs. monolinguals) as a between-subjects factor and with the probability of producing the strongest associate as the dependent variable (see Table 6). As was the case in Experiment 2, speakers produced the strongest associate more often when it was a high-frequency word than when it was a low-frequency word $\left[F(1,94)=20.24, M S_{\mathrm{e}}=0.01, p<.01, \eta_{\mathrm{p}}^{2}=.18\right]$, monolinguals were more likely than were bilinguals to produce the most common associate $[F(1,94)=20.66$, $\left.M S_{\mathrm{e}}=0.02, p<.01, \eta_{\mathrm{p}}^{2}=.18\right]$, and bilinguals were more affected by the frequency manipulation than were monolinguals $\left[F(1,94)=5.82, M S_{\mathrm{e}}=0.01, p<.05, \eta_{\mathrm{p}}^{2}=.06\right]$. As reported for response typicality, the effect of frequency on probability of producing the strongest associate was significant for bilinguals $\left[F(1,47)=19.56, M S_{\mathrm{e}}=0.01\right.$, $\left.p<.01, \eta_{\mathrm{p}}^{2}=.29\right]$ but did not reach significance for monolinguals $\left[F(1,47)=2.79, M S_{\mathrm{e}}=0.01, p=.10, \eta_{\mathrm{p}}^{2}=.06\right]$. However, in contrast with the results for response typicality, the difference between monolinguals and bilinguals was robust for both cues with high-frequency $[F(1,94)=$ 9.83, $\left.M S_{\mathrm{e}}=0.01, p<.01, \eta_{\mathrm{p}}^{2}=.10\right]$ and cues with lowfrequency $\left[F(1,94)=23.93, M S_{\mathrm{e}}=0.02, p<.01, \eta_{\mathrm{p}}^{2}=\right.$ $.20]$ associates.

As in previous experiments, we provide item trends in an appendix (Appendix C), which lists differences between speaker groups for each item.

\section{GENERAL DISCUSSION}

We investigated the effects of bilingualism on the word association task with the joint goals of to better understand bilingualism and to reveal the nature of the connections between the language system and representations of meaning. In all three experiments, bilinguals were significantly more likely to produce responses not listed in the norms than were monolinguals. Also in all three experiments, bilinguals produced significantly different association responses than did monolinguals in some conditions, but not in others. In Experiment 1, bilinguals produced less common association responses than did monolinguals (i.e., lower FSG from the Nelson et al., 1998, norms) when given cues with a single very strong associate (e.g., flipper-dolphin), but differences between speaker groups were smaller (and in the opposite direction) when given cues with multiple weakly associated responses (e.g., CHICKEN-SOUp). In Experiment 2, bilinguals produced association responses that were as typical as were those of monolinguals when both cue and associate were cognates, but produced different responses when the cue and associate were noncognates. In both Experiments 2 and 3, bilinguals produced responses that were as typical as those of monolinguals if the associate was a high-frequency word, but produced significantly different responses if the associate was a low-frequency word. Cognate status (in Experiment 2) and high associate frequency (in Experiments 2 and 3) also increased the probability that bilinguals would produce the strongest associate, although in these analyses, the differences between bilinguals and monolinguals were somewhat more persistent, and frequency was more powerful than was cognate status for reducing the difference between bilinguals and monolinguals. Importantly, in both experiments, bilinguals, but not monolinguals, exhibited an effect of associate frequency on association responses. The observation of a bilingual effect on semantic associations in some, but not in other, cases provides leverage for identifying the processing locus of these differences.

We began our investigation with the assumptions that the association task is effectively the "gold standard" task for assessing processing differences that arise at a semantic level and that the association task is relatively immune to the influence of lexical retrieval (de Groot, 1989; Nelson et al., 2005). Indeed, speakers are given freedom to produce whichever words come to mind, and the task is not timed (which reduces emphasis on lexical accesssensitive variables such as frequency). On these bases, we argued that models proposing that knowledge of two languages influences the nature of semantic representations (e.g., Ameel et al., 2009; Boroditsky, 2001) predict that bilinguals and monolinguals should produce different types of responses in the association task. As such, our finding of significant differences between groups in all experiments - at least at face value - seems to support these claims. However, in some cases, effects that appear to be semantic instead arise at a lexical processing locus, specifically during language production. We suggest that the finding of cognate and frequency effects on bilinguals' association responses implies a nonsemantic locus for the observed differences between groups. Although these effects are likely to take place during production (it is after all the frequency of the associate that affects bilinguals' responses), the cognate effects are less clearly localized since both the cognateness of the cue and that of the associate were needed to produce the cognate effect.

As is reviewed above, multiple studies have documented cognate effects on bilingual language processing. The critical difference between cognates and noncognates is overlap in form, and as such, cognate effects are typically attributed to a lexical or sublexical processing locus (for a review of the possible loci of cognate effects in language production, see Costa, Santesteban, \& Caño, 2005). On this view, cognate-cognate pairs facilitate recognition and production of the cue and the associate (Costa et al., 2000; Gollan \& Acenas, 2004; van Hell \& Dijkstra, 2002), leading bilinguals to produce the same types of responses as monolinguals did in the association task. In contrast, when tested with noncognate cues that have noncognate associates, bilinguals may have more difficulty rapidly processing the cues and retrieving the associates' names, and, instead, produce responses that are different from 
those of monolinguals. Note that, on this view, form similarity between translation equivalents does not lead to differences in processing at a semantic level and bilinguals effectively do not differ from monolinguals at a semantic level-but rather in the ability to gain access to meaning via words in each language. The finding that cognate status of the associate interacts with word frequency (a variable known to influence lexical retrieval) could be taken as further support for the conclusion that cognate status also affected lexical retrieval (and not semantics). Note, however, that this conclusion is based on the assumption that information is processed in discrete stages in the language system and on possibly flawed logic (Antón-Méndez \& Hartsuiker, 2010) equating interaction with interactivity.

An alternative view of cognate representation is that form similarity leads to activation of greater overlap for translation equivalents at a semantic processing level relative to noncognate translations (van Hell \& de Groot, 1998). On this view, cognates are semantically more similar across languages than are noncognates. This claim was supported by a bilingual word association study in which bilinguals produced associations either in (1) the same language as the cue or (2) a different language than the cue. When given cognate cues, bilinguals produced more translation-equivalent responses across languages than when given noncognate cues (van Hell \& de Groot, 1998). However, the notion of a semantic locus for cognate effects has been disputed on the basis of other evidence. For example, when bilinguals rate similarity of meaning and similarity of word form between translations independently, these ratings are not correlated (Tokowicz, Kroll, de Groot, \& van Hell, 2002). Moreover, in the present context, the proposal of greater semantic overlap for cognates than for noncognates could lead to some problematic predictions.

Specifically, in our study, bilinguals performed more like monolinguals in the semantic association task for cognate-cognate pairs. Assuming a semantic locus for cognate effects, if one learns two languages at an early age, cognates should reflect semantic associations established in both languages, effectively inheriting associations developed between languages and leading to greater overlap between languages. Conversely, noncognates should reflect semantic associations that are acquired separately in each language. Thus, in the association task, bilinguals should have differed most from monolinguals for cognate-cognate pairs, because noncognatenoncognate pairs would have acquired their semantic representations exclusively with the influence of English (and therefore - at least in theory - resembling monolinguals to a greater extent), whereas cognate associations would be influenced more by associations in Spanish. In light of the frequency-of-associate effects that we observed-a factor that van Hell and de Groot (1998) did not control for or analyze in their experiments - it seems possible that the differences they observed in responses given withinand between-language conditions were due not so much to the activation of different conceptual representations across languages, but to differences in lexical accessibility of the corresponding responses in the two languages. In any event, we suggest that - at minimum - at this stage, more evidence would be needed to support the claim that cognate status (a form-level similarity between languages) could influence processing at a semantic locus. In addition, it could be argued that more evidence is needed for an effect of cognate status on bilingual association responses; in our data, the evidence for a frequency effect on bilingual responses was considerably more robust (e.g., the interaction between participant type and cognate status was not significant for probability of producing the strongest associate).

It might be asked whether vocabulary knowledge, rather than difficulty with retrieval, produced the bilingual effects we have reported here. Although the bilinguals we tested are probably not as proficient in English as were the monolinguals (Gollan et al., 2008) and certainly know fewer very low-frequency words than do the monolinguals (Gollan \& Brown, 2006), our results, in this case, almost certainly could not be attributed to vocabulary differences. First, the bilinguals who participated in these experiments were early bilinguals, immersed in an English-dominant environment, were attending a highly selective university for which English proficiency is required, and rated themselves as highly proficient in English (see Table 1). Moreover, the materials we used were not very difficult (see the appendixes), and therefore would be unlikely to reveal any differences in vocabulary scores between the two speaker groups.

What our results clearly demonstrate is that the semantic association task is subject to nonsemantic influences, and they also demonstrate how bilingual effects that initially seem to be semantic may instead originate at a lexical retrieval locus (including the bilingual disadvantage in semantic fluency, as discussed in the introduction). In Experiments 2 and 3, we confirmed the absence of a frequency effect on association responses in monolinguals (Nelson et al., 2005) but demonstrated a robust frequency effect on association responses in bilinguals. The absence of a frequency effect in monolinguals, coupled with the presence of a frequency effect in bilinguals on association responses, is consistent with previous observations of greater frequency effects in picture naming by bilinguals relative to monolinguals (Gollan et al., 2008; Ivanova \& Costa, 2008) and suggests that differences between speaker groups are related to retrieval difficulty in bilinguals. Because associate frequency did not eliminate bilingual effects entirely (e.g., see Experiment 3 concern-

Table 7

Mean Response Typicality (Association Strength) of Responses Given by Patients With Alzheimer's Disease and Age-Matched Controls to Cues With Low- and High-Frequency Associates

\begin{tabular}{lccccc}
\hline & \multicolumn{2}{c}{$\begin{array}{c}\text { High-Frequency } \\
\text { Associate }(n=12)\end{array}$} & & \multicolumn{2}{c}{$\begin{array}{c}\text { Low-Frequency } \\
\text { Associate }(n=14)\end{array}$} \\
\cline { 2 - 3 } \cline { 5 - 6 } Speaker Group & $M$ & $S D$ & & $M$ & $S D$ \\
\hline Alzheimer's patients & .37 & .13 & & .29 & .11 \\
Controls & .46 & .11 & & .37 & .11 \\
\hline
\end{tabular}


ing probability of producing strongest associate analyses), the possibility of a small but partially semantic effect on association responses remains open. However, our results clearly imply that the first stumbling block for bilinguals is not semantic, but rather is linked to difficulty in retrieving low-frequency associates. Our focus here was on frequency of the associate because of documented differences between bilinguals and monolinguals for retrieving low-frequency words in production. At least in principle, cue frequency could have a similar effect (but see Duyck, Vanderelst, Desmet, \& Hartsuiker, 2008).

Word frequency having been identified as an important factor for understanding how bilingualism influences semantic association responses, it was of interest to consider the possible role of frequency effects on association responses in a different population. Specifically, the bilingual effect reported in Experiment 1 resembles results from comparisons between monolinguals with Alzheimer's disease (AD) and healthy controls: Patients produced less typical responses than did controls only to strong, but not to weak, cues (Gollan et al., 2006). In that study, it was proposed that the $\mathrm{AD}$ effect arises at a semantic processing level. If frequency effects do not arise at a semantic level (for a review, see Almeida et al., 2007), and if the AD effect was purely semantic and not retrieval based, the AD effect on association response should not be modulated by frequency. To consider this possibility, we conducted a reanalysis of the published AD data. Using the same frequency cutoffs as those used for the analysis of frequency in Experiment 2 ( 70 counts per million), there were 14 strong cues with low-frequency associates and 12 strong cues with high-frequency associates in the materials from Gollan et al. (2006; see Table 7).

First, association responses demonstrated a robust frequency effect; speakers produced more typical responses when the strongest associate was a high-frequency word $\left[F(1,36)=20.74, M S_{\mathrm{e}}=0.007, p<.01, \eta_{\mathrm{p}}^{2}=0.37\right]$. In this case, the frequency effect was robust in both speaker groups (both $p \mathrm{~s} \leq .01$ ). Thus, like bilinguals, healthy elderly monolinguals and monolinguals with AD exhibited a clear influence of nonsemantic factors (i.e., lexical accessibility) on responses produced in the association task. In addition, patients with $\mathrm{AD}$ produced less typical responses than did healthy elderly controls $[F(1,36)=$ 7.73, $\left.M S_{\mathrm{e}}=0.019, p=.01, \eta_{\mathrm{p}}^{2}=0.18\right]$, and, quite unlike the bilingual effect on association responses, the $\mathrm{AD}$ effect was not modulated by frequency (i.e., there was no interaction; $F<1$ ). If anything, the difference between patients and controls in response typicality was slightly smaller for cues with low-frequency associates (.08) than it was for cues with high-frequency associates (.10).

Together with the experiments presented here, these analyses demonstrate population effects that arise at different processing levels. The bilingual effect on association response arises at the locus of lexical retrieval and, therefore, is modulated by word frequency and cognate status. In contrast, the $\mathrm{AD}$ effect arises at a semantic level (for reviews, see McGlinchey-Berroth \& Milberg, 1993; Nebes, 1989, 1992; Ober, Shenaut, \& Reed, 1995) and, therefore, is not modulated by word frequency (but see Thompson-Schill, Gabrieli, \& Fleischman, 1999).

Couched in more broadly relevant terms, the results we obtained reveal that the semantic association task is not quite as purely semantic as has been previously proposed. Instead, the gold-standard task, which is thought to exclusively reflect the organization of meaning representations, is also susceptible to influences from lexical access processes (in bilinguals and in aging monolinguals). Given the present results, it seems wise to consider how ease of lexical access may influence association responses in future investigations and to take this into consideration when developing accounts of semantic memory based on speakers' responses in the association task.

\section{AUTHOR NOTE}

Both authors made equal contributions to this article and are listed in alphabetical order. This research was supported by an R01 Grant from NICHD (HD050287) and by a Career Development Award from NIDCD (DC00191), both awarded to T.H.G.; by an R01 Grant from NIH (HD051030) awarded to Victor S. Ferreira; and by a P50 (AG05131) Grant from NIH/NIA given to the University of California. Correspondence concerning this article should be addressed to I. Antón-Méndez, Discipline of Psychology, School of Behavioural, Cognitive and Social Sciences, University of New England, Armidale, NSW 2351, Australia (e-mail: iantonme@une.edu.au).

\section{REFERENCES}

Alario, F.-X., Costa, A., \& Caramazza, A. (2002). Frequency effects in noun phrase production: Implications for models of lexical access. Language \& Cognitive Processes, 17, 299-319. doi:10.1080/01690960143000236

Almeida, J., Knobel, M., Finkbeiner, M., \& Caramazza, A. (2007). The locus of the frequency effect in picture naming: When recognizing is not enough. Psychonomic Bulletin \& Review, 14, 1177-1182.

Ameel, E., Malt, B. C., Storms, G., \& Van Assche, F. (2009). Semantic convergence in the bilingual lexicon. Journal of Memory \& Language, 60, 270-290. doi:10.1016/j.jml.2008.10.001

Antón-MÉndeZ, I., \& Hartsuiker, R. J. (2010). Morphophonological and conceptual effects on Dutch subject-verb agreement. Language \& Cognitive Processes, 25, 728-748.

Azuma, T., Bayles, K. A., Cruz, R. F., Tomoeda, C. K., Wood, J. A., McGeagh, A., \& Montgomery, E. B., Jr. (1997). Comparing the difficulty of letter, semantic and name fluency tests for normal elderly and patients with Parkinson's disease. Neuropsychology, 11, 488-497. doi:10.1037/0894-4105.11.4.488

BaAyen, R. H., Piepenbrock, R., \& Gulikers, L. (1995). The CELEX lexical database [CD-ROM]. Philadelphia: Linguistic Data Consortium, University of Pennsylvania.

Bialystok, E., Craik, F. I. M., \& LuK, G. (2008). Cognitive control and lexical access in younger and older bilinguals. Journal of Experimental Psychology: Learning, Memory, \& Cognition, 34, 859-873. doi:10.1037/0278-7393.34.4.859

Boroditsky, L. (2001). Does language shape thought? Mandarin and English speakers' conceptions of time. Cognitive Psychology, 43, 1-22. doi:10.1006/cogp.2001.0748

Costa, A., Caramazza, A., \& Sebastián-Gallés, N. (2000). The cognate facilitation effect: Implications for models of lexical access. Journal of Experimental Psychology: Learning, Memory, \& Cognition, 26, 1283-1296. doi:10.1037/0278-7393.26.5.1283

Costa, A., Hernández, M., Costa, J., \& Sebastián-Gallés, N. (2009). On the bilingual advantage in conflict processing: Now you see it, now you don't. Cognition, 113, 135-149. doi:10.1016/j .cognition.2009.08.001

Costa, A., Santesteban, M., \& Caño, A. (2005). On the facilitatory effects of cognate words in bilingual speech production. Brain \& Language, 94, 94-103. doi:10.1016/j.bandl.2004.12.002 
De Deyne, S., \& Storms, G. (2008). Word associations: Network and semantic properties. Behavior Research Methods, 40, 213-231. doi:10.3758/BRM.40.1.213

DE Groot, A. M. B. (1989). Representational aspects of word imageability and word frequency as assessed through word association. Journal of Experimental Psychology: Learning, Memory, \& Cognition, 15, 824-845. doi:10.1037/0278-7393.15.5.824

DELL, G. S. (1990). Effects of frequency and vocabulary type on phonological speech errors. Language \& Cognitive Processes, 5, 313-349.

Doyle, A.-B., Champagne, M., \& Segalowitz, N. (1978). Some issues in the assessment of linguistic consequences of early bilingualism. In M. Paradis (Ed.), Aspects of bilingualism (pp. 13-20). Columbia, SC: Hornbeam Press.

Duyck, W., Vanderelst, D., Desmet, T., \& Hartsuiker, R. J. (2008). The frequency effect in second-language visual word recognition. Psychonomic Bulletin \& Review, 15, 850-855. doi:10.3758/ PBR.15.4.850

Gollan, T. H., \& Acenas, L. A. (2004). What is a TOT? Cognate and translation effects on tip-of-the-tongue states in Spanish-English and Tagalog-English bilinguals. Journal of Experimental Psychology: Learning, Memory, \& Cognition, 30, 246-269. doi:10.1037/0278 $-7393.30 .1 .246$

Gollan, T. H., \& Brown, A. S. (2006). From the tip-of-the-tongue (TOT) data to theoretical implications in two steps: When more TOTs means better retrieval. Journal of Experimental Psychology: General, 130, 462-483. doi:10.1037/0096-3445.135.3.462

Gollan, T. H., Fennema-Notestine, C., Montoya, R. I., \& JerniGAN, T. L. (2007). The bilingual effect on Boston Naming Test performance. Journal of the International Neuropsychological Society, 13, 197-208. doi:10.1017/S1355617707070038

Gollan, T. H., \& Ferreira, V. S. (2009). Should I stay or should I switch? A cost-benefit analysis of voluntary language switching in young and aging bilinguals. Journal of Experimental Psychology: Learning, Memory, \& Cognition, 35, 640-665. doi:10.1037/a0014981

Gollan, T. H., Montoya, R. I., Cera, C., \& Sandoval, T. C. (2008). More use almost always means a smaller frequency effect: Aging, bilingualism, and the weaker links hypothesis. Journal of Memory \& Language, 58, 787-814. doi:10.1016/j.jml.2007.07.001

Gollan, T. H., Montoya, R. I., \& Werner, G. A. (2002). Semantic and letter fluency in Spanish-English bilinguals. Neuropsychology, 16, 562-576. doi:10.1037/0894-4105.16.4.562

Gollan, T. H., Salmon, D. P., \& Paxton, J. L. (2006). Word association in early Alzheimer's disease. Brain \& Language, 99, 289-303. doi:10.1016/j.bandl.2005.07.001

Gollan, T. H., \& SilverberG, N. B. (2001). Tip-of-the-tongue states in Hebrew-English bilinguals. Bilingualism: Language \& Cognition, 4, 63-83. doi:10.1017/S136672890100013X

Griffin, Z. M., \& Bock, K. (1998). Constraint, word frequency, and the relationship between lexical processing levels in spoken word production. Journal of Memory \& Language, 38, 331-338. doi:10.1006/ jmla.1997.2547

Hare, M., Jones, M. N., Thomson, C., Kelly, S., \& McRae, K. (2009). Activating event knowledge. Cognition, 111, 151-167. doi:10.1016/j .cognition.2009.01.009

Ivanova, I., \& Costa, A. (2008). Does bilingualism hamper lexical access in speech production? Acta Psychologica, 127, 277-288. doi:10.1016/j.actpsy.2007.06.003

Jescheniak, J. D., \& LeVelt, W. J. M. (1994). Word frequency effects in speech production: Retrieval of syntactic information and of phonological form. Journal of Experimental Psychology: Learning, Memory, \& Cognition, 20, 824-843.

Kittredge, A. K., Dell, G. S., Verkuilen, J., \& Schwartz, M. F. (2008). Where is the effect of frequency in word production? Insights from aphasic picture-naming errors. Cognitive Neuropsychology, 25, 463-492. doi:10.1080/02643290701674851

Kolers, P. A. (1963). Interlingual word associations. Journal of Verbal Learning \& Verbal Behavior, 2, 291-300.

Kroll, J. F., Bobв, S. C., Misra, M., \& Guo, T. (2008). Language selection in bilingual speech: Evidence for inhibitory processes. Acta Psychologica, 128, 416-430. doi:10.1016/j.actpsy.2008.02.001

Kroll, J. F., \& ToKowicz, N. (2005). Models of bilingual representation and processing: Looking back and to the future. In J. F. Kroll \&
A. M. B. de Groot (Eds.), Handbook of bilingualism: Psycholinguistic approaches (pp. 531-553). New York: Oxford University Press.

Luo, L., LuK, G., \& Bialystok, E. (2010). Effect of language proficiency and executive control on verbal fluency performance in bilinguals. Cognition, 114, 29-41. doi:10.1016/j.cognition.2009.08.014

McGlinchey-Berroth, R., \& Milberg, W. P. (1993). Preserved semantic memory structure in Alzheimer's disease. In J. Cerella, J. M. Rybash, W. Hoyer, \& M. L. Commons (Eds.), Adult information processing: Limits on loss (pp. 407-422). San Diego, CA: Academic Press.

Nebes, R. D. (1989). Semantic memory in Alzheimer's disease. Psychological Bulletin, 106, 377-394.

Nebes, R. D. (1992). Cognitive dysfunction in Alzheimer's disease. In F. I. M. Craik \& T. A. Salthouse (Eds.), The handbook of aging and cognition (pp. 373-446). Hillsdale, NJ: Erlbaum.

Nelson, D. L., Dyrdal, G. M., \& Goodmon, L. B. (2005). What is preexisting strength? Predicting free association probabilities, similarity ratings, and cued recall probabilities. Psychonomic Bulletin \& Review, 12, 711-719.

Nelson, D. L., McEvoy, C. L., \& Schreiber, T. A. (1998). The University of South Florida word association, rhyme, and word fragment norms. Retrieved May 12, 2010, from http://cyber.acomp.usf.edu/ FreeAssociation/.

NiCOLADIS, E. (2003). Cross-linguistic transfer in deverbal compounds of preschool bilingual children. Bilingualism: Language \& Cognition, 6, 17-31. doi:10.1017/S1366728903001019

NiCOLADIS, E. (2006). Cross-linguistic transfer in adjective-noun strings by preschool bilingual children. Bilingualism: Language \& Cognition, 9, 15-32. doi:10.1017/S136672890500235X

Nicoladis, E., \& Genesee, F. (1996). Word awareness in second language learners and bilingual children. Language Awareness, 5, 80-90.

Ober, B. A., Shenaut, G. K., \& Reed, B. R. (1995). Assessment of associative relations in Alzheimer's disease: Evidence for preservation of semantic memory. Aging \& Cognition, 2, 254-267. doi:10 $.1080 / 13825589508256602$

Oller, D., Pearson, B. Z., \& Cobo-Lewis, A. B. (2007). Profile effects in early bilingual language and literacy. Applied Psycholinguistics, 28, 191-230. doi:10.1017/S0142716407070117

Pearson, B. Z. (1998). Assessing lexical development in bilingual babies and toddlers. International Journal of Bilingualism, 2, 347-372.

Pearson, B. Z., Fernández, S. C., \& Oller, D. K. (1993). Lexical development in bilingual infants and toddlers: Comparison to monolingual norms. Language Learning, 43, 93-120.

Portocarrero, J. S., Burright, R. G., \& Donovick, P. J. (2007). Vocabulary and verbal fluency of bilingual and monolingual college students. Archives of Clinical Neuropsychology, 22, 415-422. doi:10.1016/j.acn.2007.01.015

RANSDEll, S. E., \& Fischler, I. (1987). Memory in a monolingual mode: When are bilinguals at a disadvantage? Journal of Memory \& Language, 26, 392-405. doi:10.1016/0749-596X(87)90098-2

Roberts, P. M., Garcia, L. J., Desrochers, A., \& Hernandez, D. (2002). English performance of proficient bilingual adults on the Boston Naming Test. Aphasiology, 16, 635-645. doi:10 $.1080 / 02687030244000220$

Rosenblum, T., \& Pinker, S. A. (1983). Word magic revisited: Monolingual and bilingual children's understanding of the word-object relationship. Child Development, 53, 773-780.

Rosselli, M., Ardila, A., Araujo, K., Weekes, V. A., Caracciolo, V., Padilla, M., \& Ostrosky-Solis, F. (2000). Verbal fluency and repetition skills in healthy older Spanish-English bilinguals. Applied Neuropsychology, 7, 17-24. doi:10.1207/S15324826AN0701_3

Sandoval, T. C., Gollan, T. H., Ferreira, V. S., \& Salmon, D. P. (2010). What causes the bilingual disadvantage in verbal fluency? The dual-task analogy. Bilingualism: Language \& Cognition, 13, 231-252.

Santesteban, M., Costa, A., Pontin, S., \& Navarrete, E. (2006). The effect of word-frequency on lexical selection in speech production: Evidence from semantic homogeneous naming contexts. Cognitiva, 18, 75-84. doi:10.1174/021435506775462436

Thompson-Schill, S. L., Gabrieli, J. D. E., \& Fleischman, D. A. (1999). Effects of structural similarity and name frequency on picture naming in Alzheimer's disease. Journal of the International Neuropsychological Society, 5, 659-667. doi:10.1017/S1355617799577084

Tokowicz, N., \& Kroll, J. F. (2007). Number of meanings and 
concreteness: Consequences of ambiguity within and across languages. Language \& Cognitive Processes, 22, 727-779. doi:10.1080/ 01690960601057068

Tokowicz, N., Kroll, J. F., de Groot, A. M. B., \& van Hell, J. G. (2002). Number-of-translation norms for Dutch-English translation pairs: A new tool for examining language production. Behavior Research Methods, Instruments, \& Computers, 34, 435-451.

van Hell, J. G., \& DE Groot, A. M. B. (1998). Conceptual representation in bilingual memory: Effects of concreteness and cognate status in word association. Bilingualism: Language \& Cognition, 1, 193211. doi: $10.1017 / \mathrm{S} 1366728998000352$

van Hell, J. G., \& Dijkstra, T. (2002). Foreign language knowledge can influence native language performance in exclusively native contexts. Psychonomic Bulletin \& Review, 9, 780-789.

YAN, S., \& Nicoladis, E. (2009). Finding le mot juste: Differences between bilingual and monolingual children's lexical access in comprehension and production. Bilingualism: Language \& Cognition, 12, 323-335. doi:10.1017/S1366728909990101
NOTE

1. Additional exploratory analyses revealed that cognate-cognate pairs may have had a greater number of alternative associates that were also cognates and, therefore, were also easier for bilinguals to produce. For example, the most common associate of the cognate-cognate cue addiction (adicción) was drug (droga), but other cognate associates produced were also cognates-liquor (licor), alcohol (alcohol), and illness (enfermedad). In contrast, the most common associate of the noncognate-noncognate cue laugh (reir) is cry (llorar), and other associates were noncognates-funny (gracioso), joke (chiste, broma), and humor (humor). Thus, the presence of alternative associates that were also cognates may have reduced differences between bilinguals and monolinguals in the cognate-cognate condition. However, we did not manipulate or match between conditions for the number of weakly associated alternative cognate responses; thus, we can only speculate as to whether the cognate status of alternative associates was influential here.

APPENDIXA

List of Items Used in Experiment 1, Including Their Frequency and the Mean Difference in Response Typicality (FSG) Between Monolinguals and Bilinguals (Excluding Responses That Were Not in the Association Norms)

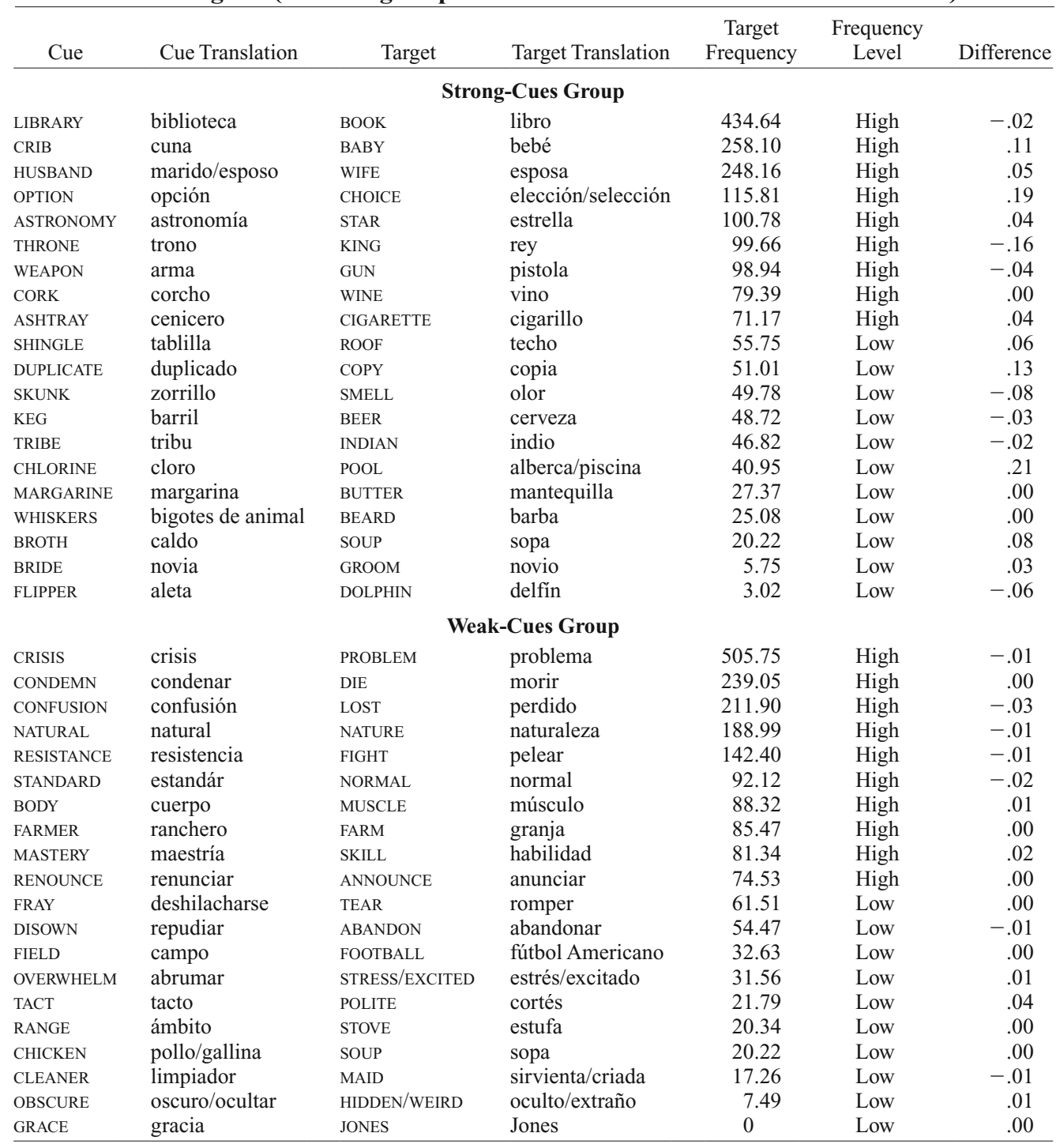


APPENDIX B

List of Items Used in Experiment 2, Including Their Frequency and Associated Difference in Response Typicality (FSG) Between Monolinguals and Bilinguals (Excluding Responses That Were Not in the Association Norms)

\begin{tabular}{|c|c|c|c|c|c|c|}
\hline Cue & $\begin{array}{c}\text { Cue } \\
\text { Translation }\end{array}$ & Target & $\begin{array}{c}\text { Target } \\
\text { Translation }\end{array}$ & $\begin{array}{c}\text { Target } \\
\text { Frequency }\end{array}$ & $\begin{array}{c}\text { Frequency } \\
\text { Level }\end{array}$ & Difference \\
\hline \multicolumn{7}{|c|}{ Cognate-Cognate Pairs } \\
\hline COUNT & contar & NUMBER & número & 406.26 & High & -.05 \\
\hline NOTION & noción & IDEA & idea & 398.44 & High & .11 \\
\hline HOUR & hora & MINUTE & minuto & 283.41 & High & .03 \\
\hline zOO & zoológico & ANIMAL & animal & 260.22 & High & .04 \\
\hline MINUTE & minuto & SECOND & segundo & 258.55 & High & -.01 \\
\hline CABLE & cable & TELEVISION & televisión & 114.13 & High & .02 \\
\hline ASTRONOMY & astronomía & STAR & estrella & 100.78 & High & -.01 \\
\hline NICOTINE & nicotina & CIGARETTE & cigarrillo & 71.17 & High & -.06 \\
\hline TOTAL & total & SUM & suma & 48.27 & Low & .01 \\
\hline ADDICTION & adicción & DRUG & droga & 47.26 & Low & -.02 \\
\hline PRESCRIPTION & prescripción & DRUG & droga & 47.26 & Low & .03 \\
\hline TRIBE & tribu & INDIAN & indio & 46.82 & Low & .00 \\
\hline PRECISE & preciso & EXACT & exacto & 29.72 & Low & .02 \\
\hline SERENE & sereno & CALM & calmar & 25.36 & Low & .00 \\
\hline ARTERY & arteria & VEIN & vena & 15.03 & Low & .05 \\
\hline KETCHUP & catsup & MUSTARD & mostaza & 4.69 & Low & .08 \\
\hline POPEYE & Popeye & SPINACH & espinaca & 4.13 & Low & .00 \\
\hline CONDITIONER & acondicionador & SHAMPOO & champú & 2.18 & Low & .02 \\
\hline \multicolumn{7}{|c|}{ Cognate-Noncognate Pairs } \\
\hline PONDER & pensar & THINK & pensar & $2,004.13$ & High & .01 \\
\hline COMPACT & compacto & SMALL & pequeño & 601.45 & High & -.01 \\
\hline CELEBRATION & celebración & PARTY & fiesta & 450.78 & High & .02 \\
\hline FINAL & final & END & final & 434.75 & High & -.02 \\
\hline DOLLARS & dólares & MONEY & dinero & 403.69 & High & -.04 \\
\hline CENT & centavo & MONEY & dinero & 403.69 & High & -.05 \\
\hline VETERAN & veterano & WAR & guerra & 362.23 & High & .06 \\
\hline ARCTIC & ártico & COLD & frío & 165.70 & High & .01 \\
\hline RODEO & rodeo & HORSE & caballo & 132.51 & High & -.02 \\
\hline THRONE & trono & KING & rey & 99.66 & High & .03 \\
\hline DOZEN & docena & TWELVE & doce & 70.73 & High & .05 \\
\hline CALENDAR & calendario & DATE & fecha & 63.35 & Low & .02 \\
\hline HUMOR & humor & FUNNY & gracioso & 50.84 & Low & -.02 \\
\hline CHLORINE & cloro & POOL & alberca & 40.95 & Low & .01 \\
\hline REPTILE & reptil & SNAKE & víbora & 23.02 & Low & .01 \\
\hline TOASTER & tostador & OVEN & horno & 19.72 & Low & .05 \\
\hline CONVENT & convento & NUN & monja & 10.45 & Low & -.03 \\
\hline ALUMINUM & aluminio & CAN & lata & 9.27 & Low & .01 \\
\hline \multicolumn{7}{|c|}{ Noncognate-Cognate Pairs } \\
\hline ALIKE & parecido & DIFFERENT & diferente & 400.56 & High & .00 \\
\hline BUMPER & parachoques & CAR & carro & 354.30 & High & .03 \\
\hline DASHBOARD & tablero & CAR & carro & 354.30 & High & .00 \\
\hline BASSINET & moisés & BABY & bebé & 258.10 & High & .08 \\
\hline VENT & respiradero & AIR & aire & 251.51 & High & -.01 \\
\hline SHEET & sábana & PAPER & papel & 225.64 & High & .01 \\
\hline SHERIFF & jerife & POLICE & policía & 206.37 & High & -.05 \\
\hline RAILROAD & ferrocarril & TRAIN & tren & 81.62 & High & -.03 \\
\hline CORK & corcho & WINE & vino & 79.39 & High & .07 \\
\hline FUEL & combustible & GAS & gas & 77.26 & High & -.02 \\
\hline ASHTRAY & cenicero & CIGARETTE & cigarrillo & 71.17 & High & -.06 \\
\hline CUCUMBER & pepino & VEGETABLES & vegetales & 58.66 & Low & .02 \\
\hline GAVEL & martillo & JUDGE & juez & 58.66 & Low & .06 \\
\hline SLACKS & pantalones & PANTS & pantalón & 15.75 & Low & .06 \\
\hline GEM & joya & DIAMOND & diamante & 14.30 & Low & .01 \\
\hline REEF & arrecife & CORAL & coral & 5.30 & Low & .05 \\
\hline MOLTEN & fundido & LAVA & lava & 3.52 & Low & .02 \\
\hline FLIPPER & aleta & DOLPHIN & delfín & 3.02 & Low & -.03 \\
\hline
\end{tabular}


APPENDIX B (Continued)

\begin{tabular}{|c|c|c|c|c|c|c|}
\hline Cue & $\begin{array}{c}\text { Cue } \\
\text { Translation }\end{array}$ & Target & $\begin{array}{c}\text { Target } \\
\text { Translation }\end{array}$ & $\begin{array}{c}\text { Target } \\
\text { Frequency }\end{array}$ & $\begin{array}{c}\text { Frequency } \\
\text { Level }\end{array}$ & Difference \\
\hline \multicolumn{7}{|c|}{ Noncognate-Noncognate Pairs } \\
\hline FINGERS & dedos & HANDS & manos & 725.31 & High & .06 \\
\hline FIST & puño & HAND & mano & 725.30 & High & .01 \\
\hline HUGE & enorme & SMALL & pequeño & 601.45 & High & -.02 \\
\hline HALF & mitad & WHOLE & entero & 320.39 & High & -.01 \\
\hline LAUGH & reír & CRY & llorar & 120.56 & High & .00 \\
\hline SOCCER & fútbol & BALL & pelota & 111.51 & High & .06 \\
\hline WINGS & agujeta & BIRD & pájaro & 102.85 & High & .07 \\
\hline SOCKS & calcetines & SHOES & zapatos & 79.16 & High & .03 \\
\hline SHOELACE & cinta & TIE & atar & 61.45 & Low & -.01 \\
\hline KNOT & nudo & ROPE & cuerda & 41.62 & Low & .06 \\
\hline LOST & perdido & FOUND & encontrado & 30.39 & Low & -.01 \\
\hline SKILLET & sartén & PAN & cacerola & 27.32 & Low & .05 \\
\hline MOW & cortar & LAWN & césped & 26.93 & Low & .01 \\
\hline BUCKLE & hebilla & BELT & cinturón & 26.87 & Low & .00 \\
\hline COMB & peine & BRUSH & cepillo & 23.74 & Low & .04 \\
\hline FORK & tenedor & SPOON & cuchara & 15.42 & Low & .07 \\
\hline DUSTPAN & recogedor & BROOM & escoba & 7.82 & Low & .11 \\
\hline WASHER & lavadora & DRYER & secadora & 2.74 & Low & .11 \\
\hline
\end{tabular}

APPENDIX C

List of Items Used in Experiment 3, Including Their Frequency and Associated Difference in Response Typicality (FSG)

Between Monolinguals and Bilinguals (Excluding Responses That Were Not in the Association Norms)

\begin{tabular}{|c|c|c|c|c|c|}
\hline Cue & $\begin{array}{c}\text { Cue } \\
\text { Translation }\end{array}$ & Target & $\begin{array}{c}\text { Target } \\
\text { Translation }\end{array}$ & $\begin{array}{c}\text { Target } \\
\text { Frequency }\end{array}$ & Difference \\
\hline \multicolumn{6}{|c|}{ High-Frequency Associates } \\
\hline BACON & bacon & EGGS & huevos & 86.03 & .01 \\
\hline BANKER & banquero & MONEY & dinero & 403.69 & .00 \\
\hline BOUQUET & ramo & FLOWERS & flores & 93.52 & -.02 \\
\hline BREEZE & brisa & WIND & viento & 120.11 & .15 \\
\hline BRIEF & breve & SHORT & corto & 201.84 & -.06 \\
\hline CASHIER & cajero & MONEY & dinero & 403.69 & .04 \\
\hline COMPASS & brujula & DIRECTION & direccion & 108.38 & -.07 \\
\hline CORK & corcho & WINE & vino & 79.39 & .01 \\
\hline CRIB & cuna & BABY & bebe & 258.10 & .00 \\
\hline CROW & cuervo & BIRD & pajaro & 102.85 & .01 \\
\hline CROWD & muchedumbre & PEOPLE & gente & $1,482.85$ & -.06 \\
\hline DAIRY & lacteo & MILK & leche & 100.11 & -.08 \\
\hline DOCK & muelle & BOAT & barca & 76.42 & .09 \\
\hline FABLE & fabula & STORY & historia & 228.49 & .03 \\
\hline FLAME & llama & FIRE & fuego & 162.29 & -.02 \\
\hline HURT & herido & PAIN & dolor & 84.09 & -.09 \\
\hline KITE & cometa & FLY & volar & 95.81 & .04 \\
\hline LOBE & lobulo & EAR & oreja & 87.71 & .03 \\
\hline MATTRESS & colchon & BED & cama & 269.89 & -.04 \\
\hline POOR & pobre & RICH & rico & 113.74 & .19 \\
\hline PRINT & imprimir & WRITE & escribir & 464.64 & .01 \\
\hline PROFIT & ganancia & MONEY & dinero & 403.69 & -.03 \\
\hline SADDLE & silla de montar & HORSE & caballo & 132.51 & .00 \\
\hline SHUTTER & persiana & WINDOW & ventana & 200.22 & .10 \\
\hline SISTER & hermana & BROTHER & hermano & 138.44 & .03 \\
\hline SOFT & blando & HARD & duro & 207.04 & .12 \\
\hline SPLINTER & astilla & WOOD & madera & 97.37 & .05 \\
\hline TELLER & contador & BANK & banco & 172.57 & .04 \\
\hline THIGH & muslo & LEG & pierna & 175.42 & .01 \\
\hline TILE & azulejo & FLOOR & suelo & 176.03 & -.03 \\
\hline TOES & dedos & FEET & pies & 327.21 & -.01 \\
\hline \multicolumn{6}{|c|}{ Low-Frequency Associates } \\
\hline ANTLER & cornamenta & DEER & ciervo & 11.73 & .09 \\
\hline ARROW & flecha & BOW & arco & 12.57 & .00 \\
\hline ASHTRAY & cenicero & CIGARETTE & cigarrillo & 4.47 & -.01 \\
\hline BREAD & pan & BUTTER & mantequilla & 27.37 & .01 \\
\hline
\end{tabular}


APPENDIX C (Continued)

\begin{tabular}{|c|c|c|c|c|c|}
\hline Cue & $\begin{array}{c}\text { Cue } \\
\text { Translation }\end{array}$ & Target & $\begin{array}{c}\text { Target } \\
\text { Translation }\end{array}$ & $\begin{array}{c}\text { Target } \\
\text { Frequency }\end{array}$ & Difference \\
\hline BRIDE & novia & GROOM & novio & 5.75 & .14 \\
\hline BUBBLE & burbuja & GUM & chicle & 8.60 & .02 \\
\hline BULL & toro & COW & vaca & 40.28 & -.01 \\
\hline CUB & cria & BEAR & oso & 16.20 & .00 \\
\hline DENIM & vaquero & JEANS & vaquero & 12.79 & -.02 \\
\hline DENTIST & dentista & TEETH & dientes & 3.13 & .06 \\
\hline DILL & eneldo & PICKLE & en vinagre & 3.58 & .01 \\
\hline DINNER & cena & SUPPER & cena & 27.60 & .03 \\
\hline FAWN & cervatillo & DEER & ciervo & 11.73 & .12 \\
\hline GRANDMA & abuela & GRANDPA & abuelo & 1.56 & .04 \\
\hline JIGSAW & rompecabezas & PUZZLE & puzzle & 8.71 & .02 \\
\hline LEAP & salto & JUMP & salto & 66.76 & .05 \\
\hline LOOSE & suelto & TIGHT & apretado & 38.99 & .00 \\
\hline LOSER & perdedor & WINNER & ganador & 17.04 & .13 \\
\hline MARSH & pantano & SWAMP & cienaga & 7.49 & .04 \\
\hline MIST & neblina & FOG & niebla & 9.89 & -.01 \\
\hline PEEL & peladura & ORANGE & naranja & 19.61 & .09 \\
\hline PUB & bar & BEER & cerveza & 48.71 & .06 \\
\hline REFLECT & reflejar & MIRROR & espejo & 49.16 & .00 \\
\hline SPOON & cuchara & FORK & tenedor & 14.86 & .16 \\
\hline STEPS & escalones & STAIRS & escaleras & 44.08 & .00 \\
\hline STING & picar & BEE & abeja & 16.65 & -.04 \\
\hline STRONG & fuerte & WEAK & debil & 59.39 & .03 \\
\hline SUNRISE & amanecer & SUNSET & puesta de sol & 10.10 & .08 \\
\hline SYRUP & jarabe & PANCAKES & crepes & 2.57 & -.06 \\
\hline THIN & fino & FAT & gordo & 57.32 & .06 \\
\hline TOAD & sapo & FROG & rana & 9.39 & -.04 \\
\hline
\end{tabular}

aExpected translations are listed. Alternative acceptable translations are possible for several items.

(Manuscript received May 26, 2009;

revision accepted for publication March 3, 2010.) 